\title{
Tobacco excise tax increase and illicit cigarette consumption: evidence from Vietnam
}

\author{
Anh Nguyen $\quad$ (1) , ${ }^{1}$ Hoang The Nguyen ${ }^{2}$
}

${ }^{1}$ Economics, Development and Policies Research Center, Hanoi, Viet Nam

${ }^{2}$ Economics, Development and Policies Research Center, Hanoi, Viet Nam

\section{Correspondence to}

Dr Anh Nguyen, Economics, Development and Policies

Research Center, Hanoi 12, Viet Nam; anhnguyen@depocen.org

Previous version of the paper was presented at Tobacconomics Session, 11th Vietnam Economist Annual Meeting (VEAM 2018) at Foreign Trade University, Hanoi, Vietnam. All errors are our own.

Received 18 July 2019 Revised 29 September 2019 Accepted 11 October 2019 Published Online First 10 February 2020

\section{ABSTRACT}

Background One of the most significant barriers to tax reform and tax rate increases in Vietnam is the threat of illicit trade promulgated by the tobacco industry. The industry argues that higher taxes will stimulate smuggling, thereby undermining tax policy objectives and impairing the domestic tobacco manufacturing. Unfortunately, there is a dearth of updated and independent studies to verify this claim and inform the tax reform in the country.

Objectives The present paper attempts to generate new estimates of the illicit consumption and compare them to a prior study to ascertain the changes in the levels of the illicit trade after a tobacco excise tax increase.

Methods The study uses primary data collected from the Tobacco Consumption Survey in late 2017. It is a multistage cluster random household survey, covering a sample size of over 2700 smokers, and purposively designed to make its results comparable to prior estimates, which have been done before the tax increase. Particularly, we collect packs from selected smokers and perform careful inspection to identify the prevalence of illicit products. In addition to the consumption, we collect data on brand choices, cigarette prices, the types of stores that the smokers bought their cigarettes, as well as their socioeconomic characteristics. They allow us to determine the regional variation of the illicit trade, identify the main illicit cigarette brands, compare the prices of the licit and illicit cigarettes, and examine the main sources of the illicit cigarettes. Incomes of the licit and illicit cigarette smokers are also compared.

Results Contrary to the tobacco industry's predictions, our estimates demonstrate that the level of the illicit trade declined even after the increase of taxes imposed on tobacco products in Vietnam. The illicit cigarettes account for only about $13.72 \%$ of the total cigarette consumption in Vietnam in 2017, lower than the $20.7 \%$ estimate in 2012 done by the previous study. The illicit cigarettes are heavily concentrated in the southern provinces of Vietnam bordering Cambodia, and locally accessible to the smokers from grocery stores. Jet and Hero are the two most popular brands, representing over $80 \%$ of total illicit consumption in the country. Interestingly, the illicit cigarettes are on average more expensive than the illicit products in Vietnam, unlike many other countries where the former are typically cheaper than the latter. Consequently, as is to be expected, the illicit cigarette smokers tend to earn higher incomes than those smoking the licit products.

Conclusions Raising the taxes levied on tobacco does not necessarily cause higher illicit consumption in Vietnam as widely stated by the tobacco industry. The Government of Vietnam should recognise the tobacco tax policy as the most effective and cost-effective tobacco control measure and establish a clear road map of progressive tobacco excise tax increases so that total tax levied on tobacco accounts for at least $75 \%$ of retail price as suggested by the WHO to reduce smoking prevalence in the country.

\section{INTRODUCTION}

Smoking remains a serious public health problem in Vietnam despite the fact that Vietnam became a party to the WHO Framework Convention on Tobacco Control as early as 17 March 2005, and the government has taken various measures to reduce tobacco consumption. The country is ranked among those with the highest smoking prevalence worldwide. About 15.6 million adults smoke tobacco, and among them, 12.6 million adults smoke cigarettes, accounting for approximately $22.5 \%$ and $18.2 \%$ of the adult population in Vietnam in 2015, respectively. ${ }^{1}$ Furthermore, about 40000 people are dying in Vietnam each year due to tobacco-related illnesses, and without proper measures, this is estimated to reach 70000 deaths per year by $2030 .^{2}$

Raising tobacco taxes has proven to be the most effective and cost-effective way of reducing smoking, ${ }^{3}$ and the WHO recommends that the tobacco taxes in total should account for at least $75 \%$ of the retail price. ${ }^{4}$ Unfortunately, the taxes imposed on tobacco remains modest in Vietnam. In addition to a valued-added tax of $10 \%$ of the retail price, domestically manufactured tobacco is subject to an excise tax. The excise tax was increased to $70 \%$ of ex-factory prices starting in January 2016, and to $75 \%$ in January 2019. It is Vietnam's practice of using ex-factory prices that makes the tax rate seem high. Under this scheme, however, the excise tax can be manipulated by undervaluing the ex-factory prices, which is exactly what is happening in Vietnam. ${ }^{5}$ Consequently, the current total tobacco tax accounts for only about $36 \%$ of the retail price of the most popular cigarette brand in Vietnam. ${ }^{4}$

One of the most significant barriers to tax reform and tax rate increases is the threat of illicit trade promulgated by tobacco industry. The industry argues that higher taxes will result in increases in the illicit consumption, thereby undermining the tax policy objectives and impairing the domestic tobacco manufacturing. This prediction runs contrary to the prevailing evidence found in many developed and developing countries that increases in tax rates have not undermined the policy objectives. ${ }^{6}$ Unfortunately, most of previous studies were either directly funded or indirectly related to the tobacco industry, which overestimates the illicit trade level and government tax revenue loss to 
oppose raising tobacco tax. ${ }^{7}$ Updated and independent studies to provide objective and reliable estimates of the illicit consumption in Vietnam are of critical shortage, deterring the Government of Vietnam from putting forward more radical tax reform agenda. Consequently, the tobacco taxes remain relatively low in the country.

Only two studies have attempted to provide objective estimates of the problem. Focusing on an earlier period from 1990 to 2010 Nguyen $e a^{8} l^{8}$ used two methods to estimate illicit consumption in the country. They first compare consumption estimates from different national household surveys (ie, the Vietnam Living Standards Survey in 1998, the Vietnam Household Living Standard Survey in 2006, the Vietnam National Health Survey in 2002 and the Global Adult Tobacco Survey in 2010) with cigarette tax data acquired from the government. They then estimate the difference between Vietnam's officially recorded imports and exports to the country as officially recorded by each of its trading partners. Their two methods yield significantly different estimates of illicit trade. The results of their first method are sensitive to the assumed levels of consumption under-reporting, highly variant across years (ranging from as low as $0.66 \%$ to as much as $20.19 \%$ of total consumption) and even turn negative in 2010. The second method in general produces higher estimates (11.4\%-21.1\%).

Nguyen $e t a l^{9}$ use a different and preferred approach, relying on primary data collected from the nationally representative Vietnam Illicit Trade Assessment in 2012 (VITA 2012). The illicit consumption is identified by examining smokers' cigarette packs. Their results, which will be discussed in more details later in this paper show that the illicit trade accounts for about 20.7\% of the total domestic consumption in 2012. These two studies, though very useful, may not be directly relevant for the current debate on a tobacco excise increase as they focus on the period before the Government of Vietnam embarked on the tobacco tax reform in 2014 and implemented the tax increase in 2016.

This study aims to meet the critical demand for reliable data in service to the current policy debate. The increase in the ad valorem excise tax rate in 2016 provides a unique opportunity to assess the effect of the tax increases on the illicit trade in Vietnam. The research attempts to generate new estimates of the illicit consumption in the country and compare them to prior estimates to ascertain changes in the levels of the illicit trade before and after the tobacco excise tax increase. It also measures geographical variation in the illicit trade, particularly in the context of proximity to borders, associations between the illicit consumption and socioeconomic factors, as well as changes in the patterns of the illicit trade including the source of product and price points. The findings derived from the study are critical to inform and to support ongoing tax policy discussion in the Ministry of Finance and National Assembly in the country.

\section{DATA AND METHODOLOGY}

The study uses primary data collected from the Tobacco Consumption Survey in 2017 (TCS 2017). Specifically, it is a household survey, covering a sample size of over 2700 smokers. The target population consists of men and women aged 18 years and above, who currently smoke manufactured cigarettes at least once a week. The survey is designed to measure the illicit trade in Vietnam, and to make its results comparable with the VITA 2012. ${ }^{9}$

In order to do this, we replicated the cluster sampling strategy of VITA 2012 and used the same survey instrument. In particular, multistage stratified cluster random sampling is employed.
In the first stage, among 12 provinces surveyed in VITA 2012, 9 are chosen in our study. Due to resource constraint, we select three provinces in each of three spatial and socioeconomic regions (North, Central and South) while VITA 2012 selected four provinces in each region. All the three largest cities/provinces namely Hanoi, Da Nang and Ho Chi Minh City are covered in both surveys. In the second stage, we stratified and randomly selected districts, then communes and villages from these selected nine provinces, resulting in a total of 135 villages. The survey was stratified by rural and urban dimension. In the final stage, at each selected village we performed screening activities and constructed a sampling frame of households in which a smoker could be identified. We then randomly select households from the list of smoker households.

The questionnaire is adapted from VITA 2012 with only a few modifications to take into account policy changes during the last few years, especially the National Law on Tobacco Control in 2012 with the requirement that a pictorial health warning label be printed on all cigarette packs. In addition to inperson interviews with smokers, we collect cigarette packs in their most recent purchases and perform careful inspections to identify the prevalence of illicit cigarettes. In general, two principal features are examined: the presence of a tax stamp, and the use of valid text and pictorial health warning labels as per Circular No. 05/2013/TTLT-BYT-BCT jointly issued by the Ministry of Health and the Ministry of Finance in 2013. Furthermore, places from which the smokers purchased the cigarettes are used to distinguish between tax avoidance and evasion. Eventually, a cigarette pack is classified as illicit if it has neither a tax stamp nor proper health warning labels and it was not bought from duty-free shops or abroad. Combined with data on the smokers' cigarette consumption, this information allows us to estimate the level of the illicit trade in Vietnam. In addition to the consumption, we collected data on brand choices, cigarette prices as well as the types of stores that the smokers bought their cigarettes from, as well as on the smokers' socioeconomic characteristics, including incomes. They are used to examine the patterns and identify the likely determinants of the illicit consumption.

Our general estimation approach is as follows. The consumption is aggregated by summing individual consumption, which is annualised by multiplying quantity consumed daily by 365 days. The level of the illicit trade is obtained by dividing the estimated total annual consumption of smokers, whose packs are identified as illicit products by that of all smokers. Prices are measured per 20-cigarette pack. The incomes of the smokers and of their households are reported on a monthly basis in local currency. All calculations are weighted by sampling weights.

\section{RESULTS}

Table 1 presents our estimated rate of the illicit consumption in Vietnam in 2017, together with the results in $2012^{9}$ for comparison. About $13.72 \%$ of the manufactured cigarettes consumed are illicit in 2017 , nearly six percentage points lower than in 2012. All of the illicit products detected are foreign brands and smuggled into the country. When comparing across the regions, a dominant share (over 84\%) of them is consumed in the South.

Table 2 reports the shares accounted for by the main illicit brands as well as their graphical distribution. Hero and Jet continue to be the most popular brands in the country's illicit market in 2017. The two brands together account for over $80 \%$ of the illicit consumption in the country, and are mostly smoked in the South (over 90\%). The Jet and Hero cigarettes are legally imported to Cambodia and Indonesia where they are 


\begin{tabular}{|c|c|c|}
\hline & TCS 2017 & VITA 2012 \\
\hline \multirow[t]{2}{*}{ Overall } & 13.72 & 20.7 \\
\hline & (11.85 to 15.83 ) & \\
\hline \multicolumn{3}{|l|}{ By origin } \\
\hline Domestic & 0.00 & $\mathrm{~N} / \mathrm{A}$ \\
\hline Foreign & 100.00 & $\mathrm{~N} / \mathrm{A}$ \\
\hline \multicolumn{3}{|l|}{ By region } \\
\hline \multirow[t]{2}{*}{ North } & 10.02 & 7.1 \\
\hline & (4.54 to 20.7 ) & \\
\hline \multirow[t]{2}{*}{ Central } & 5.85 & 5.6 \\
\hline & (3.48 to 9.69 ) & \\
\hline \multirow[t]{2}{*}{ South } & 84.13 & 87.3 \\
\hline & (74.75 to 90.47 ) & \\
\hline
\end{tabular}

The TCS 2017 results are estimated by the authors while the VITA 2012 results are retrieved from the prior study conducted by Nguyen et al..$^{10}$ Overall represents illicit consumption's weighted share of the total cigarette consumption. Domestic and Foreign represents domestic brands' and foreign brands' weighted shares of the total illicit consumption, respectively. North, Central and South represents weighted shares corresponding to the North, Central and South regions in the national illicit market. For TCS 2017, 95\% Cls are reported in parenthesis.

TCS 2017, Tobacco Consumption Survey in 2017; VITA 2012, Vietnam Illicit Trade Assessment in 2012.

originally produced, and then smuggled across the border into the southern provinces of Vietnam, ${ }^{9}$ which possibly accounts for their exclusive geographical concentration. State Express 555 (SE555) is the third most prevalent brand. Unlike Jet and Hero, however, SE555 appears to be used more in the North (nearly $70 \%)$. There are two varieties of SE555, one manufactured locally and the other sourced illegally from abroad.

When looking at the entire cigarette market, Jet's and Hero's aggregate market share falls by almost five percentage points, from over $16 \%$ in 2012 to roughly $11 \%$ in 2017 . This decline almost equals the observed change in the illicit consumption rate (six percentage points). As the two are mostly found in the southern provinces where they are smuggled into Vietnam from Cambodia, this decline may be attributed to the particularly intensive border investigation and market surveillance led by the National and Provincial 389 Steering Committees since early 2016. The Prime Ministry approved Decision No. 389/QD-TTg to establish the National and Provincial Steering Committees (called 389 Steering Committees) for combating smuggling, commercial frauds and counterfeit goods including manufactured cigarettes in 2014. Since founded, the 389 Steering Committees have led frequent border investigations and market surveillance nationwide, and successfully uncovered and stopped numerous cases of illegal cigarette trading.

Table 3 presents the relative average prices between illicit and licit cigarettes. The illicit packs are significantly more expensive than the legal ones. This result holds in all three of the regions and is consistent with the results obtained from VITA 2012. Even more interestingly, our estimates show that it has become increasingly costly for the smokers to consume the illicit products, even after the tobacco excise tax increase. The ratio between the average price of the illicit cigarettes and that of the legal ones goes from only 1.50 in 2012 (when the ad valorem excise tax rate imposed on tobacco was $65 \%$ ) up to 2.08 in 2017 . The same results are held when specifically comparing the two varieties of SE555. The smuggled SE555 is over 70\% more expensive than the local SE555. As suggested by economic models, the higher relative price of the illicit cigarettes might cause a number of smokers to reduce their consumption, switch to cheaper, licit cigarettes, or even to quit smoking (in the best case) due to budget constraints. As a result, the share of illicit cigarettes in the national market dropped in 2017 as our research shows.

The consistent findings confirm the conclusion made in all relevant prior studies ${ }^{9}{ }^{10}$ that smokers in Vietnam are willing to pay an additional expense for illicit cigarettes rather than buy more cheaply, as many previous studies have found in most other countries worldwide. This difference is likely to stem from the fact that Vietnamese consumers usually perceive imported products to be of premium quality, and prefer them to their domestic counterparts. The same perception can be applied to buying the illicit cigarettes, all of which are foreign brands. The increase of price discrepancies between the illegal and legal cigarettes might be caused by the higher risks and costs of smuggling as well as a shortage in supply which are possibly attributable to the tremendous efforts expended by the Government of Vietnam to combat smuggling in the country, starting in early 2016.

Table 4 compares average individual and household incomes of the smokers consuming illicit cigarettes with those smoking legal ones. Illicit cigarette smokers earn significantly higher incomes (over 40\%) than legal product consumers. A similar result is also found when considering their household incomes.

Table 2 Major illicit cigarette brands and their regional distribution in Vietnam (\%)

\begin{tabular}{|c|c|c|c|c|c|c|c|c|}
\hline \multirow[b]{3}{*}{ Brand } & \multicolumn{4}{|l|}{ Market share } & \multicolumn{4}{|c|}{ Distribution by region in 2017} \\
\hline & \multicolumn{2}{|l|}{ Entire market } & \multicolumn{2}{|l|}{ Illicit market } & \multirow[b]{2}{*}{ North } & \multirow[b]{2}{*}{ Central } & \multirow[b]{2}{*}{ South } & \multirow[b]{2}{*}{ Total } \\
\hline & TCS 2017 & VITA 2012 & TCS 2017 & VITA 2012 & & & & \\
\hline \multirow[t]{2}{*}{ Hero } & 6.52 & 6.4 & 47.55 & 32.8 & 4.36 & 3.00 & 92.64 & 100 \\
\hline & (5.35 to 7.93 ) & & (40.23 to 54.98$)$ & & (0.71 to 22.52$)$ & (0.89 to 9.63$)$ & (78.87 to 97.7 ) & \\
\hline \multirow[t]{2}{*}{ Jet } & 4.79 & 10.1 & 34.94 & 52.1 & 0.00 & 8.27 & 91.73 & 100 \\
\hline & (3.83 to 5.99 ) & & (28.5 to 41.99 ) & & - & (4.39 to 15.05 ) & (84.95 to 95.61 ) & \\
\hline \multirow[t]{2}{*}{ SE555 } & 1.25 & 0.88 & 9.13 & 4.5 & 67.59 & 14.67 & 17.74 & 100 \\
\hline & (0.55 to 2.83 ) & & (4.14 to 18.95 ) & & (32.19 to 90.16$)$ & (3.08 to 48.16 ) & (4.91 to 47.4 ) & \\
\hline \multirow[t]{2}{*}{ Esse } & 0.34 & 0.99 & 2.47 & 5.1 & 40.77 & 6.55 & 52.68 & 100 \\
\hline & (0.13 to 0.88$)$ & & (0.95 to 6.27 ) & & (5.45 to 89.16$)$ & (0.6 to 44.72 ) & (10.11 to 91.68$)$ & \\
\hline \multirow[t]{2}{*}{ Craven A } & 0.28 & 0.00 & 2.04 & 0.00 & 0.00 & 0.00 & 100.00 & 100 \\
\hline & (0.09 to 0.86 ) & & (0.66 to 6.14 ) & & - & - & & \\
\hline
\end{tabular}

The TCS 2017 results are estimated by the authors while the VITA 2012 results are retrieved from the prior study conducted by Nguyen et al. ${ }^{10}$ For TCS $2017,95 \%$ Cls are reported in parenthesis.

SE555, State Express 555; TCS 2017, Tobacco Consumption Survey in 2017; VITA 2012, Vietnam Illicit Trade Assessment in 2012. 


\begin{tabular}{|c|c|c|c|c|}
\hline & TCS 2017 & & VITA 2012 & \\
\hline Cigarette type & Mean, \$ & $\begin{array}{l}\text { Ratio: } \\
\text { illicit-licit }\end{array}$ & Mean, \$ & $\begin{array}{l}\text { Ratio: } \\
\text { illicit-licit }\end{array}$ \\
\hline \multicolumn{5}{|l|}{ Overall } \\
\hline Illicit & $\begin{array}{l}0.91 \\
\text { (0.81 to } 1.01 \text { ) }\end{array}$ & 2.08 & $\begin{array}{l}0.78 \\
(0.75 \text { to } 0.82)\end{array}$ & 1.51 \\
\hline Licit & $\begin{array}{l}0.44 \\
(0.43 \text { to } 0.45 \text { ) }\end{array}$ & & $\begin{array}{l}0.52 \\
(0.49 \text { to } 0.55)\end{array}$ & \\
\hline \multicolumn{5}{|l|}{ North } \\
\hline Illicit & $\begin{array}{l}1.69 \\
\text { (1.16 to } 2.22)\end{array}$ & 4.00 & $\begin{array}{l}1.18 \\
\text { (0.93 to } 1.43 \text { ) }\end{array}$ & 2.27 \\
\hline Licit & $\begin{array}{l}0.42 \\
(0.40 \text { to } 0.44)\end{array}$ & & $\begin{array}{l}0.52 \\
(0.48 \text { to } 0.55)\end{array}$ & \\
\hline \multicolumn{5}{|l|}{ Central } \\
\hline Illicit & $\begin{array}{l}1.14 \\
\text { (0.84 to } 1.44 \text { ) }\end{array}$ & 2.58 & $\begin{array}{l}0.77 \\
\text { (0.61 to } 0.94 \text { ) }\end{array}$ & 1.75 \\
\hline Licit & $\begin{array}{l}0.44 \\
\text { (0.42 to } 0.46 \text { ) }\end{array}$ & & $\begin{array}{l}0.44 \\
\text { (0.40 to } 0.49 \text { ) }\end{array}$ & \\
\hline \multicolumn{5}{|l|}{ South } \\
\hline Illicit & $\begin{array}{l}0.80 \\
(0.78 \text { to } 0.83)\end{array}$ & 1.73 & $\begin{array}{l}0.77 \\
\text { (0.74 to } 0.79 \text { ) }\end{array}$ & 1.28 \\
\hline Licit & $\begin{array}{l}0.46 \\
\text { (0.44 to } 0.49 \text { ) }\end{array}$ & & $\begin{array}{l}0.60 \\
(0.54 \text { to } 0.67)\end{array}$ & \\
\hline \multicolumn{5}{|l|}{ SE 555} \\
\hline Illicit & $\begin{array}{l}2.10 \\
\text { (2.02 to } 2.18 \text { ) }\end{array}$ & 1.70 & $\begin{array}{l}1.58 \\
\text { (1.36 to } 1.81)\end{array}$ & 1.34 \\
\hline Licit & $\begin{array}{l}1.24 \\
\text { (1.20 to } 1.27)\end{array}$ & & $\begin{array}{l}1.18 \\
\text { (1.10 to } 1.23)\end{array}$ & \\
\hline
\end{tabular}

The TCS 2017 results are estimated by the authors while the VITA 2012 results are retrieved from the prior study conducted by Nguyen et al..$^{10}$ For TCS 2017, the International Monetary Fund (IMF) exchange rate $\$ 1.00=V N D 22425$ is used to convert the price in the local currency into US dollars. Ratio: illegal-legal is calculated by dividing the mean prices of illicit cigarettes by the mean prices of licit products. The exchange rate has no effect on the value of the ratios, and the ratios are comparable between the two studied years without having to adjust for inflation. $95 \% \mathrm{Cls}$ are reported in parenthesis. We also perform two-sample mean comparison t-tests of unweighted cigarette prices by legality with unequal variances, and it is statistically significant that the mean prices of illicit cigarettes are higher than the mean prices of licit cigarettes in all five cases. The statistical results are available on request.

SE555, State Express 555; TCS 2017, Tobacco Consumption Survey in 2017; VITA 2012, Vietnam Illicit Trade Assessment in 2012; VND, Vietnam dong.

Table 4 Comparison between incomes of smokers consuming licit and illicit cigarettes

\begin{tabular}{llll}
\hline Incomes & Illicit & Licit & Ratio \\
\hline Individual income & 7.029 & 4.924 & 1.43 \\
& $(0.807)$ & $(0.172)$ & \\
Household income & 14.008 & 10.496 & 1.33 \\
& $(1.781)$ & $(0.271)$ & \\
\hline
\end{tabular}

SEs are reported in parenthesis. The results are estimated from TCS 2017 by the authors. Incomes are reported in the local currency, million Vietnam dongs. Illicit and Licit represent smokers whose collected packs are identified as illicit products and licit products, respectively. Ratio is calculated by dividing the mean incomes of illicit cigarette smokers by the mean incomes of licit cigarette smokers. We also performed two-sample mean comparison t-tests of unweighted incomes with unequal variances between the two groups, and it is statistically significant that the mean incomes of illicit cigarette smokers are higher than the mean incomes of licit cigarette smokers. The statistical results are available on request.

TCS 2017, Tobacco Consumption Survey in 2017.
Table 5 Sources of illegal cigarettes in the last purchase (\%)

\begin{tabular}{llc}
\hline Sources & TCS 2017 & VITA 2012 \\
\hline Grocery store & 76.96 & 72.2 \\
& $(69.88$ to 82.78$)$ & 3.6 \\
\hline Tobacco shop & 6.41 & 22.7 \\
& $(3.07$ to 12.91$)$ & \\
Tea shop/coffee shop & 12.49 & \\
& $(8.42$ to 18.14$)$ & 0.1 \\
Tobacco street vendor & 3.06 & \\
& $(1.65$ to 5.62$)$ & 1.4 \\
\hline Restaurant & 0.10 & \\
\hline Other places & $(0.01$ to 0.73$)$ & 100 \\
\hline Total & 0.98 & $(0.29$ to 3.32$)$ \\
\hline The & 100 & \\
\hline
\end{tabular}

The TCS 2017 results are estimated by the authors while the VITA 2012 results are retrieved from the prior study conducted by Nguyen et al. ${ }^{10}$ For TCS 2017, 95\% Cls are reported in parentheses.

TCS 2017, Tobacco Consumption Survey in 2017; VITA 2012, Vietnam Illicit Trade Assessment in 2012.

These findings are theoretically consistent with the higher prices of illicit cigarettes, thereby strengthening the argument that buying illicit brands is more likely to reflect the smokers' preference for foreign-originated products, rather than tax evasion in Vietnam.

Table 5 shows where the smokers purchase their illicit cigarettes. Overall, illegal cigarettes are mainly sourced through informal household businesses, rather than through formally established enterprises. Over $70 \%$ of the illicit packs found are bought from grocery stores in 2012 and 2017. Tea and coffee shops are the second primary source (nearly $12.5 \%$ ), followed by tobacco shops and tobacco street vendors. A minimal share of the illegal cigarettes is purchased in restaurants, while none is obtained from supermarkets and convenience stores. Given the highly prevalent nature of the grocery stores, these findings imply that the illicit cigarettes remain locally accessible to the smokers, particularly in the North where most of the illicit consumption is found.

\section{DISCUSSION AND POLICY IMPLICATIONS}

Providing an objective measure of the illicit trade level plays a critical role in developing comprehensive and effective tobacco control policies, particularly in Vietnam where smuggling has been identified as an alarming national issue. Unfortunately, most of the currently available local estimates are either directly funded by, or related to, the tobacco industry. They constantly exaggerate the level of the illicit consumption, as well as the impact of a higher tobacco tax on it as a strategy to discourage the government from raising taxes even though extensive global evidence consistently suggests that raising the taxes levied on tobacco has had a significant impact on reducing smoking prevalence and improving government revenue. This research aims to provide local, objective evidence on the likely impact of raising tobacco taxes on the level of the illicit trade to inform and support the tax policy reform in Vietnam. We compare the new estimates from the household survey of cigarette consumption in 2017 with the previous scientifically rigorous results in 2012 to identify how illicit consumption has evolved after the tobacco excise tax increase of 2016.

Generally, our estimates demonstrate that raising the taxes levied on tobacco does not necessarily cause higher illicit 
consumption in Vietnam as widely predicted by the tobacco industry. The illicit cigarettes account for only about $13.72 \%$ of the country's total cigarette consumption in 2017, which is six percentage points lower than in 2012, the year when the increase of tobacco tax had not been implemented. Furthermore, the illicit trade is heavily concentrated in two specific brands, namely Jet and Hero, and in the South, where these two most popular illicit brands are smuggled into the country from Cambodia. This finding implies that geography plays an important role in determining the illicit trade, and that the particularly intensive campaigns led by the national and provincial 389 Steering Committees to combat the smuggling activities in the northern provinces in recent years may have contributed to reducing the rate of the illicit consumption in the country.

We also find that the illegal cigarettes are generally more expensive than the legal ones. This finding holds consistently for both throughout the country, in each of the three different socioeconomic regions, and within the particular twin-track SE555 brand. Furthermore, as expected, the illicit cigarette smokers have higher incomes than those consuming the licit packs. The results imply that Vietnamese smokers' unique preference for foreign products must be one important motivation for choosing the illicit cigarettes in Vietnam, instead of the costsaving incentive as found in many other countries worldwide. The Vietnamese consumers usually perceive imported products to be more luxurious, to have superior quality and to be associated with a higher social status than their domestically produced counterparts. The same perception can be applied to buying the illicit cigarettes, as all the illicit cigarettes recorded in our survey are foreign brands.

More strikingly, although the tobacco tax was increased from $65 \%$ to $70 \%$ in 2016 , the ratio between the mean prices of the illicit and licit cigarettes rose by approximately $40 \%$ during the period from 2012 to 2017. This increase likely stems from the supply deficit and high smuggling risk caused by the government's strict and intensive border monitoring and market inspection mentioned above. As the illicit cigarettes became increasingly more expensive, the standard economic theory suggests that some smokers may have switched to consume the more affordable, licit products, resulting in the decrease found in the illicit consumption rate.

The grocery stores turn out to be the primary places that sell the illicit cigarettes. They are legally operating, widely available and easy to access, indicating that the smuggled products remain locally accessible to the smokers, particularly in the South.

Our findings have two important policy implications. First, the Government of Vietnam should make good use of the tax policy as the most effective and cost-effective tobacco control measure by establishing a clear road map to increase the excise tax imposed on tobacco so that the total tobacco tax accounts for at least $75 \%$ of the retail price as suggested by the WHO. Raising tobacco taxes to reduce the affordability of tobacco products in Vietnam is essentially good for public health as it will spur the smokers to quit smoking and prevent non-smokers, especially the youth, from starting to smoke. Second, to effectively tackle cigarette smuggling, the Government of Vietnam should strengthen the market surveillance at retail points in the provinces close to the border in the North and the economic centres, particularly Hanoi and Ho Chi Minh City, aside from border monitoring and transportation tracing.

\section{Limitations}

The paper is subject to two limitations. First, although TCS 2017 follows a multistage cluster sampling strategy it is not designed to be a national representative sample such as the Global Adult Tobacco Survey (GATS) surveys. Instead, TCS 2017 is more purposively designed to replicate VITA 2012 in such a way that the results from the two surveys could be compared. Second, only 9 out of 12 provinces in VITA 2012 are covered in TCS 2017. Although attempts have been made to make the two surveys directly comparable, readers should be aware of the smaller geographical coverage of TCS 2017 as compared with VITA 2012.

\section{What this paper adds}

- Global evidence suggests that raising taxes on tobacco is the most effective and cost-effective way of reducing tobacco consumption, even after taking the threat of illicit cigarette trade into account. However, the lack of updated and independent studies to provide objective and reliable locally relevant estimates of illicit consumption deters the government from increasing the tobacco excise tax to combat the smoking epidemic in Vietnam.

- This paper provides new estimates of the illicit consumption and compares them with a previous study to examine the evolution of the illicit trade before and after an increase in the tobacco excise tax rate in Vietnam. We find that the rate of the illicit consumption declines significantly after the increase in the tax rate, implying that raising tobacco taxes does not necessarily cause higher illicit consumption in the country.

- Illicit cigarettes are more expensive than licit products, mostly two brands, Jet and Hero, heavily concentrated in the southern provinces, and easily obtained from local grocery stores.

Acknowledgements The authors thank Mai Nguyen, Chuc Nguyen and other colleagues at DEPOCEN for their efforts to implement the Tobacco Consumption Survey in 2017. The authors also thank Prof Frank J. Chaloupka, Dr Evan Blecher and Dr Hana Ross for their helpful comments.

Contributors Contributors AN oversaw the entire project, designed the study, reviewed an earlier draft and finalised the manuscript. HTN designed survey tools, coordinated survey implementation, analysed data and wrote an earlier draft of the manuscript.

Funding The project, including the data collection under the Tobacco Consumption Survey in 2017 is financially supported by the University of Illinois at Chicago's Institute for Health Research and Policy through its partnership with the Bloomberg Philanthropies.

Competing interests None declared.

\section{Patient consent for publication Not required.}

Ethics approval The Tobacco Consumption Survey in 2017 was conducted with ethics clearance from the Institutional Ethics Review Board at Hanoi School of Public Health, Vietnam.

Provenance and peer review Not commissioned; externally peer reviewed. Data availability statement Data are available upon reasonable request.

\section{ORCID iD}

Anh Nguyen http://orcid.org/0000-0003-2753-2667

\section{REFERENCES}

1 Ministry of Health. Global adult tobacco survey (GATS) Vietnam 2015. Hanoi, 2016

2 WHO. Tobacco: fact sheet. Available: http://www.wpro.who.int/vietnam/topics/ tobacco/factsheet/en/ [Accessed 2019 Jul 9].

3 WHO. Who report on the global tobacco epidemic, 2015: raising taxes on tobacco. Geneva, 2015. 


\section{Original research}

4 WHO. Who report on the global tobacco epidemic, 2017: monitoring tobacco use and prevention policies. Geneva, 2017.

5 Tobacconomics. Vietnam country Factsheet: tobacco Tax structures. Chicago, 2018

6 Chaloupka FJ, Yurekli A, Fong GT. Tobacco taxes as a tobacco control strategy. Tob Control 2012;21:172-80.

7 Smith KE, Savell E, Gilmore AB. What is known about tobacco industry efforts to influence tobacco Tax? A systematic review of empirical studies. Tob Control 2013;22:e1.
8 Nguyen MT, Denniston R, Nguyen HTT, et al. The empirical analysis of cigarette Tax avoidance and illicit trade in Vietnam, 1998-2010. PLoS One 2014;9:e87272.

9 Nguyen MT, Dao ST, Nguyen NQ, et al. Illicit cigarette consumption and government revenue loss in Vietnam: evidence from a primary data approach. Int J Environ Res Public Health 2019;16:1960.

10 Joossens L. Vietnam: smuggling adds value. Tob Control 2003;12:119-20. 